\title{
Role of Non Affected Side Relaxation on Function Outcome in Patient with Bell's Palsy
}

\author{
MOHAMED N. ELBAHRAWY, Ph.D.; MOHAMED H. RASHAD, Ph.D.; YOUSSEF M. ELBALAWY, Ph.D. and \\ MUSTAFA S. MOHAMED, M.Sc.
}

The Department of Physical Therapy for Neuromuscular Disorders \& its Surgery, Faculty of Physical Therapy, Cairo University

\begin{abstract}
Background: Facial paralysis is an extremely frightening situation and gives extreme stress to patients because obvious disfiguring face may cause significant functional, aesthetic, and psychological disturbances.

Aim of Study: To investigate the role of non affected side relaxation on function outcome in patient with Bell's Palsy (BP).

Patients and Methods: Thirty patients with unilateral BP were assigned into two equal groups (Group A \& Group B): Group (A) received conventional physical therapy program (laser therapy, faradic stimulation, therapeutic facial massage and facial exercise) on the affected side only while Group (B) received a designed relaxation program (Transcutaneous Electrical Nerve Stimulation (TENS), therapeutic facial massage, intraoral massage and ice massage) on the non affected side plus conventional physical therapy program on the affected side. Sunnybrook Facial Grading System (SFGS) and Electroneuronography (ENoG) were used to assess the severity of facial nerve degeneration. Assessment using both SFGS and EnoG was done pre-treatment, post one month of treatment and post two month of treatment.
\end{abstract}

Results: The study has revealed that the function outcome has improved significantly in each group with no significant difference between both groups.

Conclusion: It can be concluded that a designed relaxation program of the non-affected side has no significant effect on the function outcome in patient with Bell's palsy.

Key Words: Facial paralysis (FP) - Bell's Palsy (BP) Sunnybrook Facial Grading System (SFGS).

\section{Introduction}

BELL'S Palsy (BP) is a form of facial paralysis resulting from a dysfunction of the facial nerve. It's an inability to control facial muscles on the affected side. Several conditions can cause facial

Correspondence to: Dr. Mohamed N. El-Bahrawy, The Department of Physical Therapy for Neuromuscular Disorders \& its Surgery, Faculty of Physical Therapy, Cairo University paralysis, however if no specific cause can be identified, the condition is known as Bell's palsy. Bell's palsy is the most common acute mononeuropathy and is the most common cause of acute facial paralysis $(>80 \%)$ ). It is defined as idiopathic unilateral facial nerve paralysis, usually selflimiting. The hallmark of this condition is a rapid onset of partial or complete paralysis of facial muscles. In rare cases $(<1 \%)$, it can occur bilaterally resulting in total facial paralysis. It is thought that an inflammatory condition leads to swelling of the facial nerve [1].

Bell's palsy, a fairly common disorder predominantly prevalent in the adult age group, affects nerves and muscles in the face causing paralysis or dropping of one side of the face. Clients with Bell's palsy face many challenges including psychological, physical and emotional [2].

This syndrome of idiopathic facial paralysis was first described more than a century ago by Sir Charles Bell; yet much controversy still surrounds its etiology and management. The exact etiology of BP is unknown, but viral infection, autoimmune disease, and vascular causes have been postulated as possible pathomechanisms [3].

The prognosis of facial paralysis has been predicted based mainly on various electrophysiologic tests, including the nerve excitability test, the maximal stimulation test, electroneuronography (ENoG), and electromyography (EMG). In particular, ENoG can determine the percentage of degenerating of nerve fibers in early phase of acute facial paralysis. ENoG is considered the most valuable test to predict the prognosis and its main indication is acute complete facial paralysis. Both the percentage of degeneration and rate of degeneration are prognostic indicators [4]. 
Despite the existence of several different grading scales for measuring facial function there is so far no optimal scale. The Sunnybrook Facial grading system (SFGS) has been reported to be the best instrument for clinical use [5]

Activity of the uninvolved facial musculature, in the presence of the profound involved side facial weakness, may actually shift the face toward the uninvolved side with facial functions and expressions. Facial functions, such as closing the eye, eating and drinking, speaking, or rinsing the mouth are most difficult for those patients. The appearance of obvious facial disfigurement at rest and with movement has a major negative impact on psychosocial well-being and daily interpersonal interactions [6]

Physical therapy, in the context of Bell's palsy, mainly uses methods which increase muscle and nerve function either through exercise or electrotherapy. Thermal methods and massage work by decreasing swelling and increasing blood flow to the affected tissues thus increasing the amount of oxygen available to damaged hypoxic tissues with the aim of promoting recovery [7].

Because facial sensation is intact with Bell's palsy, massage within pain tolerance is probably not only safe, but an important intervention to keep flaccid muscles elastic and well nourished [8]

The non paralyzed side can also be targeted to create symmetry with the paralyzed or paretic side. Although the term 'synkinesis' is used to describe involuntary movement of one mimetic muscle group with the voluntary movement of a second muscle group on the affected side, 'hyperkinesis' is broadly used to define the asymmetric static and dynamic hyperactivity of the normal side [9]

Hyperactivity of the unaffected side may be evident in some patients. Face tapping and light massage may help to increase muscle relaxation [10].

A long recovery period and/or delayed complete healing could lead to a negative effect on many aspects of an individual's life. How society perceives the person could negatively influence the client's self-confidence. The management of Bell's palsy depends on the individual case and may include medication, physiotherapy and as a last option surgery [2].

\section{Material and Methods}

This study was conducted on thirty patients from both genders. Patients were assigned randomly into two equal groups. All patients were referred from neurologist after complete clinical investigation. Every patient in both groups received treatment for eight weeks; three times/week, every other day. Patients were selected from the outpatient clinic of Faculty of Physical Therapy, Cairo University and the outpatient clinic of Faculty of Medicine, Kasr Al-Aini Hospital. This randomized controlled study was conducted in the period from June 2016 to April 2019. Patients were eligible to participate in the study if they had idiopathic unilateral facial paralysis (Bell's palsy) which has been previously diagnosed by a physician, the onset did not exceed seven days and the patient's age ranged from 20-40 years old.

All patients were given a full explanation of the protocol of the study and a consent form was signed for each patient before participating in the study.

A- Evaluation procedure: Sunnybrook Facial Grading System (SBFGS) was used as a subjective method to assess facial muscles. SBFGS is a performance based measure of facial impairment in three areas: (1) Resting posture of the eye, the nasolabial (cheek) fold, and the corner of the mouth; (2) Voluntary movement for five expressions in five regions of the face; forehead wrinkles, eye closure, open mouth smile, snarl, and pucker and (3) Synkinesis (associated with the voluntary movement tests).

The electroneuronography was used as an objective method of assessment to evaluate the degree of facial nerve degeneration and predict the prognosis of patients with facial nerve palsy. It uses a maximal electrically evoked stimulus paradigm and recording technique to objectively measure the amplitude of the facial Compound Muscle Action Potential (CMAP). The ENoG value, which is the ratio of the CMAP on the paralyzed side to the healthy side, multiplied by 100 , reflects the percentage of facial nerve degeneration of the paralyzed side. ENoG of the nasolabial fold has more prognostic value in the outcomes of Bell's palsy than ENoG of the orbicularis oculi muscle.

$B$ - Treatment procedures: All participants received three sessions per week for two months. Group (A) received conventional physical therapy program (laser therapy, faradic stimulation, therapeutic facial massage and facial exercise) on the affected side only while Group (B) received a designed relaxation program (Transcutaneous Electrical Nerve Stimulation (TENS), therapeutic facial massage, intraoral massage and ice massage) on 
the non affected side plus conventional physical therapy program on the affected side.

\section{Statestical analysis:}

Results are expressed as mean \pm standard deviation or number $(\%)$. Comparison between categorical data [number (\%)] was performed using Chi square test. Test of normality, KolmogorovSmirnov test, was used to measure the distribution of data measured pre-treatment. Accordingly, comparison between normally distributed variables in the two groups was performed using unpaired $t$ test while in not normally distributed variables comparison was performed using Mann Whitney test.

- Comparison between different times of measurement in the same group was performed using Friedman ANOVA test followed by Wilcoxon Sign Rank test if significant results was recorded.

- Statistical Package for Social Sciences (SPSS) computer program (Version 19 windows) was used for data analysis. $p$-value $\leq 0.05$ was considered significant.

\section{Results}

\section{I- General characteristics of the two groups:}

Results are expressed as mean \pm Standard Deviation (SD). There was no significant difference between both groups concerning their age ( $p=$ $0.765)$, sex $(p=0.715)$ and side of involvement $(p=$ 1.000) (Table 1).

Table (1): General characteristics in the two studied groups.

\begin{tabular}{lcccl}
\hline & $\begin{array}{c}\text { Control group } \\
(\mathrm{n}=15)\end{array}$ & $\begin{array}{c}\text { Study group } \\
(\mathrm{n}=15)\end{array}$ & $\begin{array}{c}t- \\
\text { value }\end{array}$ & $\begin{array}{c}p- \\
\text { value }\end{array}$ \\
\hline Age (yrs.) & $31.33 \pm 7.50$ & $30.53 \pm 6.99$ & 0.302 & 0.765 \\
Gender: & & & & $(\mathrm{N})$ \\
$\quad$ Female & $8(53.3 \%)$ & $6(40.0 \%)$ & $\chi^{2}=$ & 0.715 \\
$\quad$ Male & $7(46.7 \%)$ & $9(60.0 \%)$ & 0.536 & $(\mathrm{NS})$ \\
Side of lesion: & & & & \\
$\quad$ Left & $8(53.3 \%)$ & $8(53.3 \%)$ & $\chi^{2}=$ & 1.000 \\
$\quad$ Right & $7(46.7 \%)$ & $7(46.7 \%)$ & 0.001 & $(\mathrm{NS})$ \\
\hline
\end{tabular}

Data are expressed as mean \pm SD or number $(\%)$.

$\chi 2$ : Chi square test.

NS: $p>0.05$ : Not Significant.

\section{II- Percent of degeneration:}

A- Between groups comparison: At pretreatment, there was no statistical significant difference between the median value of percent of degeneration in control group [72.3 (29.4-97.3)] and its corresponding value in study group [64.9 (23.2-96.2) $]$ with $Z$-value $=-0.685$ and $p$-value $=$
0.494. After 1 month of treatment, there was no statistical significant difference between the median value of percent of degeneration in control group [29.9 (0.0-96.2)] and its corresponding value in study group $[13.2(0.0-82.2)]$ with $\mathrm{Z}$-value $=-1.266$ and $p$-value $=0.205$, also after 2 months of treatment, there was no statistical significant difference between the median value of percent of degeneration in control group [12.2 (0.0-92.3)] and its corresponding value in study group [0.0 (0.0-75.9)] with $\mathrm{Z}$-value $=0.897$ and $p$-value $=0.370$ (Table 2$)$

Table (2): Between group comparison between median values of percent of degeneration in the two studied groups measured at different times of measurement.

\begin{tabular}{lllll}
\hline & $\begin{array}{c}\text { Control group Study group } \\
(\mathrm{n}=15)\end{array}$ & $\begin{array}{c}\mathrm{Z} \text { - } \\
\text { value }\end{array}$ & $\begin{array}{c}p- \\
\text { value }\end{array}$ \\
\hline Pre-treatment & 72.3 & 64.9 & -0.685 & 0.494 \\
& $(29.4-97.3)$ & $(23.2-96.2)$ & & $(\mathrm{NS})$ \\
After 1 month & 29.9 & 13.2 & -1.266 & 0.205 \\
& $(0.0-96.2)$ & $(0.0-82.2)$ & & $(\mathrm{NS})$ \\
After 2 months & 12.2 & 0.0 & -0.897 & 0.370 \\
& $(0.0-92.3)$ & $(0.0-75.9)$ & & $(\mathrm{NS})$ \\
\hline
\end{tabular}

Data are expressed as median (minimum-maximum).

Z-value: Mann Whitney test.

NS $: p>0.05$ : Not Significant.

After 1 month of treatment in control group one case recorded complete recovery, 12 cases had partial recovery and 2 cases recorded no recovery. In study group all cases recorded either complete recovery (two cases) or partial recovery (13 cases). After 2 month of treatment in control group 6 cases recorded complete recovery, 7 cases had partial recovery and 2 cases recorded no recovery. While in study group all cases recorded either complete recovery 8 cases or partial recovery 7 cases (Table 3 ).

Table (3): Percent of recovery in percent of degeneration in the two studied groups measured at different times of measurement.

\begin{tabular}{lll}
\hline & $\begin{array}{c}\text { Control group } \\
(\mathrm{n}=15)\end{array}$ & $\begin{array}{c}\text { Study group } \\
(\mathrm{n}=15)\end{array}$ \\
\hline After 1 month: & & \\
$\quad$ No recovery & $2(13.33 \%)$ & $0(0.0 \%)$ \\
Partial recovery & $12(80.0 \%)$ & $13(86.67 \%)$ \\
Complete recovery & $1(6.67 \%)$ & $2 \quad(13.33 \%)$ \\
After 2 month: & & \\
No recovery & $2(13.33 \%)$ & $0(0.0 \%)$ \\
Partial recovery & $7(46.67 \%)$ & $7(46.67 \%)$ \\
Complete recovery & $6(40.0 \%)$ & $8(53.33 \%)$ \\
\hline
\end{tabular}

Data are expressed as number (percent).

Z-value: Mann Whitney test.

NS $: p>0.05$ : Not Significant. 
B- Within group comparison: In control group, there was a statistical significant difference in the median value of percent of degeneration between different times of measurement (Chi square val$\mathrm{ue}=25.864 ; p=0.001$ ) where the median value of percent of degeneration measured after 1 month [29.9 (0.0-96.2)] and 2 months [12.2 (0.0-92.3)] of treatment were significantly decreased when compared with its corresponding value measured at pre-treatment [72.3 (29.4-97.3)] (Z-value $=3.237 ; p$-value $=0.001$ and $Z$-value $=3.408 ; p$ value $=.008$, respectively). Also, it was significantly decreased after 2 months when compared with its corresponding values measured after 1 month of treatment $(Z$-value $=3.297 ; p$-value $=0.001)$. In study group, there was a statistical significant difference in the median value of percent of degeneration between different times of measurement (Chi square value $=29.103 ; p=0.001$ ) where the median value of percent of degeneration measured after 1 month [ $13.2(0.0-82.2)]$ and 2 months [0.0 $(0.0-75.9)]$ of treatment were significantly decreased when compared with its corresponding value measured at pre-treatment [64.9 (23.2-96.2))] $(\mathrm{Z}$-value $=3.408 ; p$-value $=0.001$ and $\mathrm{Z}$-value $=$ $3.408 ; p$-value $=0.001$, respectively). Also, it was significantly decreased after 2 months when compared with its corresponding values measured after 1 month of treatment $(Z$-value $=-3.181 ; p$-value $=0.001)$ (Table 4).

Table (4): Within group comparison between median values of percent of degeneration measured at different times of measurement in the two studied groups.

\begin{tabular}{|c|c|c|c|c|c|}
\hline & Pre-treatment & After 1 month & After 2 months & $X_{2}$ value & $p$-value \\
\hline $\begin{array}{l}\text { Control group: } \\
\text { Z \& } p \text {-value vs. pre ttt } \\
\text { Z \& } p \text {-value vs. after } 1 \text { month }\end{array}$ & $\begin{array}{c}72.3(29.4-97.3) \\
- \\
-\end{array}$ & $\begin{array}{l}29.9(0.0-96.2) \\
-3.237 \& 0.001(\mathrm{~S})\end{array}$ & $\begin{array}{l}12.2(0.0-92.3) \\
-3.408 \& 0.001(\mathrm{~S}) \\
-3.297 \& 0.001(\mathrm{~S})\end{array}$ & 25.864 & $0.001(\mathrm{~S})$ \\
\hline $\begin{array}{l}\text { Study group: } \\
\qquad \mathrm{Z} \& p \text {-value vs. pre ttt } \\
\quad \mathrm{Z} \& p \text {-value vs. after } 1 \text { month }\end{array}$ & $\begin{array}{c}64.9(23.2-96.2) \\
-\end{array}$ & $\begin{array}{l}13.2(0.0-82.2) \\
-3.408 \& 0.001(\mathrm{~S})\end{array}$ & $\begin{array}{l}0.0(0.0-75.9) \\
-3.408 \& 0.001(\mathrm{~S}) \\
-3.181 \& 0.001(\mathrm{~S})\end{array}$ & 29.103 & $0.001(\mathrm{~S})$ \\
\hline
\end{tabular}

\section{III- Sunnybrook Facial Grading System (SBFGS):}

A- Between groups comparison: At pre-treatment, there was no statistical significant difference between the median value of SBFGS in control group [27.0 (10.0-32.0)] and its corresponding value in study group [28.0 (10.0-28.0)] with Zvalue $=0.301$ and $p$-value $=0.764$. After 1 month of treatment, there was no statistical significant difference between the median value of FGS in control group [64.0 (10.0-100.0)] and its corresponding value in study group [88.0 (24.0-100.0] with $Z$-value $=-1.396$ and $p$-value $=0.163$. Also after 2 months of treatment, there was no statistical significant difference between the median value

Table (5): Between group comparison between median values of SBFGS in the two studied groups measured at different times of measurement.

\begin{tabular}{lllll}
\hline & $\begin{array}{c}\text { Control group } \\
(\mathrm{n}=15)\end{array}$ & $\begin{array}{c}\text { Study group } \\
(\mathrm{n}=15)\end{array}$ & $\begin{array}{c}\mathrm{Z} \text { - } \\
\text { value }\end{array}$ & $\begin{array}{c}p \text { - } \\
\text { value }\end{array}$ \\
\hline Pre-treatment & 27.0 & 28.0 & -0.301 & 0.764 \\
& $(10.0-32.0)$ & $(10.0-28.0)$ & & $(\mathrm{NS})$ \\
After 1 month & 64.0 & 88.0 & -1.396 & 0.163 \\
& $(10.0-100.0)$ & $(24.0-100.0)$ & & $(\mathrm{NS})$ \\
After 2 months & 80.0 & 100.0 & -1.029 & 0.304 \\
& $(20.0-100.0)$ & $(28.0-100.0)$ & & $(\mathrm{NS})$ \\
\hline
\end{tabular}

Data are expressed as median (minimum-maximum).

Z-value: Mann Whitney test. $\quad$ NS: $p>0.05$ : Not Significant. of FGS in control group [80.0 (20.0-100.0)] and its corresponding value in study group [100.0 (28.0100.0)] with $\mathrm{Z}$-value $=-1.029$ and $p$-value $=0.304$ (Table 5).

After 1 month of treatment in control group one case recorded complete recovery, 13 cases had partial recovery and 1 case recorded no recovery. In study group all cases recorded either complete recovery (two cases) or partial recovery (13 cases). After 2 month of treatment in control group 6 cases recorded complete recovery and 9 cases had partial recovery while in study group 8 cases recorded complete recovery and 7 cases had partial recovery (Table 6).

Table (6): Percent of recovery in percent of degeneration in the two studied groups measured at different times of measurement.

\begin{tabular}{lll}
\hline & $\begin{array}{c}\text { Control group } \\
(\mathrm{n}=15)\end{array}$ & $\begin{array}{c}\text { Study group } \\
(\mathrm{n}=15)\end{array}$ \\
\hline After 1 month: & $1(6.67 \%)$ & $0(0.0 \%)$ \\
No recovery & $13(86.6 \%)$ & $13(86.67 \%)$ \\
Partial recovery & $1(6.67 \%)$ & $2(13.33 \%)$ \\
Complete recovery & & \\
After 2 month: & $2(0.0 \%)$ & $0(0.0 \%)$ \\
No recovery & $7(60.0 \%)$ & $7(46.67 \%)$ \\
Partial recovery & $6(40.0 \%)$ & $8(53.33 \%)$ \\
Complete recovery & & \\
\hline
\end{tabular}

Data are expressed as number (percent). 
B- Within group comparison: In control group, there was a statistical significant difference in the median value of FGS between different times of measurement $($ Chi square value $=28.526 ; p=0.001$ ) where the median value of FGS measured after 1 month [64.0 (10.0-100.0)] and 2 months [80.0 (20.0-100.0)] of treatment were significantly increased when compared with its corresponding value measured at pre-treatment [27.0 (10.0-32.0)] $(\mathrm{Z}$-value $=-3.299 ; p$-value $=0.001$ and $\mathrm{Z}$-value $=-3.412 ; p$-value $=0.001$, respectively). Also, it was significantly increased after 2 months when compared with its corresponding values measured after 1 month of treatment $(\mathrm{Z}$-value $=-3.187 ; p$ - value $=0.001$ ). In study group, there was a statistical significant difference in the median value of FGS between different times of measurement (Chi square value $=29.103 ; p=0.001)$ where the median value of FGS measured after 1 month [88.0 (24.0-100.0)] and 2 months [100.0 (28.0-100.0)] of treatment were significantly increased when compared with its corresponding value measured at pre-treatment [28.0 (10.0-28.0)] $(\mathrm{Z}$-value $=-3.422 ; p$-value $=0.001$ and $Z$-value $=-3.433 ; p$-value $=0.001$, respectively). Also, it was significantly increased after 2 months when compared with its corresponding values measured after 1 month of treatment (Z-value= $-3.201 ; p$-value $=0.001)($ Table 7$)$.

Table (7): Within group comparison between median values of SBFGS measured at different times of measurement in the two studied groups.

\begin{tabular}{|c|c|c|c|c|c|}
\hline & Pre-treatment & After 1 month & After 2 months & $\mathrm{x} 2$ value & $p$-value \\
\hline $\begin{array}{l}\text { Control group: } \\
\mathrm{Z} \& p \text {-value vs. pre ttt } \\
\mathrm{Z} \& p \text {-value vs. after } 1 \text { month }\end{array}$ & $\begin{array}{c}27.0(10.0-32.0) \\
- \\
-\end{array}$ & $\begin{array}{l}64.0(10.0-100.0) \\
-3.299 \& 0.001(\mathrm{~S})\end{array}$ & $\begin{array}{l}80.0(20.0-100.0) \\
-3.412 \& 0.001(\mathrm{~S}) \\
-3.187 \& 0.001(\mathrm{~S})\end{array}$ & 28.526 & 0.001 \\
\hline $\begin{array}{l}\text { Study group: } \\
\qquad \mathrm{Z} \& p \text {-value vs. pre ttt } \\
\text { Z \& p-value vs. after } 1 \text { month }\end{array}$ & $\begin{array}{c}28.0(10.0-28.0) \\
-\end{array}$ & $\begin{array}{l}88.0(24.0-100.0) \\
-3.422 \& 0.001(\mathrm{~S})\end{array}$ & $\begin{array}{l}100.0(28.0-100.0) \\
-3.433 \& 0.001(\mathrm{~S}) \\
-3.201 \& 0.001(\mathrm{~S})\end{array}$ & 29.103 & 0.001 \\
\hline $\begin{array}{l}\text { Data are expressed as median (minir } \\
\mathrm{X}^{2} \text { : Chi square of Friedman ANOVA }\end{array}$ & n-maximum). & $\begin{array}{l}\text { Z-value: } \\
\mathrm{S} \quad: l\end{array}$ & $\begin{array}{l}\text { lcoxon Sign Rank test. } \\
\text { 0.05: Significant. }\end{array}$ & & \\
\hline
\end{tabular}

\section{Discussion}

From the table showing the percent of recovery for both groups, a slight improvement of the study group could be noticed when compared to the control group, although this improvement was not statistically significant it could be in favor to the treatment program selected for the study group. A noticeable improvement may have taken place if the duration of the treatment or number of patient has been increased.

Also the percent of recovery table for both groups has revealed how reliable the SBFGS is. If we compared between the percentages of recovery in both methods of assessment we'll find out that the change was almost the same between both methods, this result was supported by [5], she stated that the SFGS has been reported to be the best instrument for clinical use. That finding comes in advantage for countries going through economic crisis or patients with low income who cannot afford going through computerized methods of assessment.

The main findings of the current study confirmed that there was no significant improvement regarding the percent of degeneration \& FGS score between both groups. However there was a signif- icant improvement within each group when the percent of degeneration and FGS score were statistically analyzed, that explains what [11] have proved that the majority of cases of Bells palsy recover with conservative treatment. As well as [12] who stated that patients diagnosed with Bell's palsy may expect complete recovery without medical and/or physiotherapy intervention.

[1] has also stated that most people recover spontaneously and achieve near-normal to normal functions. Many show signs of improvement as early as 10 days after the onset, even without treatment. Moreover [13] have concluded that many patients with Bell's palsy will experience improvement in their facial nerve function without treatment. The study group, which received both conventional physical therapy program on the affected side and designed relaxation program on the non affected side showed nearly the same improvement as control group and that's what [14] stated that almost all patients with acute Bell's palsy showed spontaneous recovery wither they received physical therapy program or they don't.

The result also agrees with [7] that mentioned that there is no high quality evidence to support significant benefit or harm from any physical therapy for idiopathic facial paralysis. There is low 
quality evidence that facial exercise reduces sequelae in acute cases.

The results of the study is closely similar to [15] who have stated that after one month of doing two different programs in two exercise and biofeedback groups, remarkable increase of quality of life and also improvement of function of face were noticed in each group, but there was not any significant difference between quality of life and function of face in two groups.

[16] has also stated that the efficacy of facial rehabilitation has been shown in patients with longstanding facial paresis (at least 9 months) by several observational studies. In contrast, the efficacy of facial rehabilitation in early/acute stages is more complex to calculate because of the high rate of spontaneous recovery. However the statistical result disagrees with [17], whom tested the effect of electrical stimulation and active muscle contractions in Bell's palsy on 30 patients of early diagnosis and found out that both groups showed improvement but there was significant improvement on HBS Scale in group treated with electrical stimulation and active muscle contractions.

The results also disagree with [12]. He stated that patients suffering from Bell's palsy may benefit from specific categorical physiotherapy treatments designed to improve physical functioning as well as social well-being.

To our best knowledge, there are no randomized controlled trials on the role of non affected side relaxation on function outcome in patient with Bell's palsy in Egypt. So, the current study is the first randomized controlled study to investigate the role of non affected side relaxation on function outcome in patient with Bell's palsy in Egypt.

\section{References}

1- Aishwarya Balakrishnan: Bell's palsy: Causes, symptoms, diagnosis and treatment. Journal of Pharmaceutical Sciences and Research, Vol. 7 (11), 2015.

2- LUTFIA ALI ELLSAHLI: The management of Bell's palsy at selected community health centers in the cape metropolitan district of the Western Cape South Africa, university of the Western Cape Faculty of Community and Health Sciences, 22-33, 2015.

3- HAMDY N. EL-TALLAWYA, WAFAA M.A. FARGHALYA, GHAYDAA A. SHEHATAA, REDA BADRYA, MAHMOUD HASSANB, MOHAMED A. HAMEDA, MOHAMED A.M. SAYEDC, KHALED O. ABDULGHANID, SAYED S. SAYEDE, TAREK A. RAGEHA, NABIL A. METWALLYB, KHALED O. MOHAMEDA and AMAL M. TOHAMYA: Incidence and clinical predictors of outcome of Bell's palsy, The Egyptian Journal of Neurology, Psychiatry and Neurosurgery, 53 (2): 703, 2016.
4- DONG-HEE LEE: Clinical efficacy of electroneuronography in acute facial paralysis. Journal Audiol Otol., 20 (1): 8-12, 2016.

5- SARA AXELSSON: Bell's palsy-Medical Treatment and Influence of Prognostic Factors. Department of Otorhinolaryngology, Lund University, 108 p. 2013.

6- JESSIE VANSWEARINGEN: Facial Rehabilitation: A Neuromuscular Reeducation, Patient-Centered Approach. Facial Plastic Surgery, 24: 250-9, 2008.

7- LÁZARO J. TEIXEIRA1, JULIANA S. VALBUZA2 and GILMAR F. PRADO: Physical therapy for Bell's palsy (idiopathic facial paralysis). Cochrane Database of Systematic Reviews 2011, Issue 12. Art. No.: CD006283. DOI: 10.1002/14651858. CD006283.pub3.2012.

8- RUTH WERNER: A Massage Therapist's Guide to Pathology (Baltimore: Lippincott Williams \& Wilkins), 2009.

9- JONATHAN A. CABIN, GUY G. MASSRY and BABAK AZIZZADEH: Botulinum toxin in the management of facial paralysis, 23 (4): 2, 2015.

10- NOVAK B.: Rehabilitation strategies for facial nerve injuries Seminars in Plastic Surg., 18: 47-51, 2004.

11- DIVYA H.R., RAJITH and GOVINDEGOWDA K.M.: Etiopathological factors and management of facial palsy. Asian Pac. J. Health Sci., 1 (4): 377-84, 2014.

12- JAMES M. ELLIOTT: Physiotherapy treatment of Bell's Palsy: A case report. New Zealand Journal of Physiotherapy, 34 (3): 167-71, 2006.

13- JOHN R. De ALMEIDA, GORDON H. GUYATT, SACHIN SUD, JOANNE DORION, MICHAEL D. HILL, MICHAEL R. KOLBER, JANE LEA, SYLVIA LOONG REG, BALVINDER K. SOMOGYI BSW, BRIAN D. WESTERBERG, CHRIS WHITE and JOSEPH M. CHEN: Management of Bell palsy: Clinical practice guideline. Canadian Medical Association Journal, 86 (12): 917-22, 2014.

14- MARIA NICASTRI, PATRIZIA MANCINI, DANIELE De SETA, GIANANTONIO BERTOLI, LUCA PROSPERINI, DANILO TONI, MAURIZIO INGHILLERI, and ROBERTO FILIPO: Efficacy of Early Physical Therapy in Severe Bell's palsy: A Randomized Controlled Trial. Neuro rehabilitation and Neural Repair, 27 (6): 542-51, 2013

15- NAVID MIRZAKHANI, LEILA ANGOOTI OSHNARI, ALIREZA AKBARZADEH BAGHBAN, DARIUOSH ELIYSPOOR, ATIYEH JAVANTASH, MAHVASH KAMALIFAR and TAYEBEH PARSAMANESH: The Comparison between Exercise Therapy and Biofeedback Therapy in Facial Function and Quality Of Life of Bell's palsy. Journal of Clinical Physiotherapy Research, 2 (3): 139-43.,2017.

16-MARGARIDA FERREIRA, ELISA E. MARQUES, JOSÉ A. DUARTE and PAULA C. SANTOS: Physical Therapy with Drug Treatment in Bell Palsy. American Journal of Physical Medicine \& Rehabilitation, Vol. 94, No. 4. 3318, 2015.

17- GITANJALI R. PATIL and SURAJ B. KANASE: Effect of Electrical Stimulation and Active Muscle Contractions in Bell's Palsy. International Journal of Science and Research (IJSR), Vol. 6, 655. 2017. 


\section{دور إسترخاء الجانب الغير مصاب على النتائج الوظيفية النية

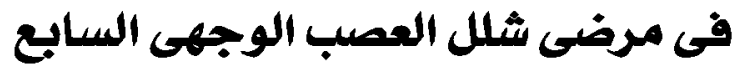

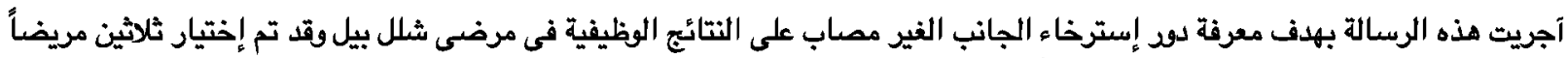

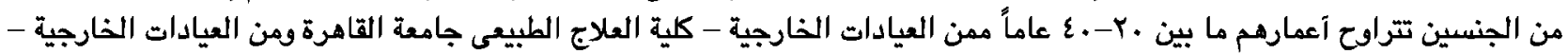

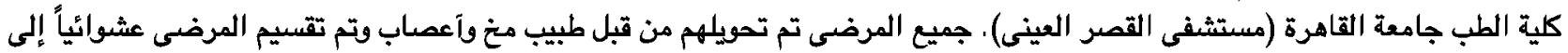

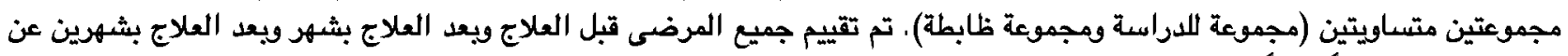

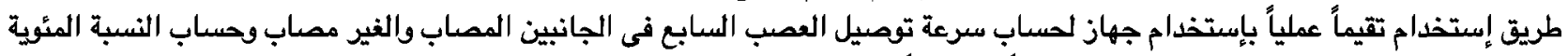

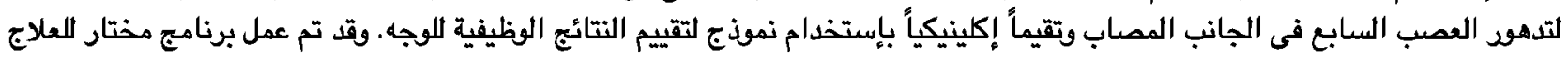

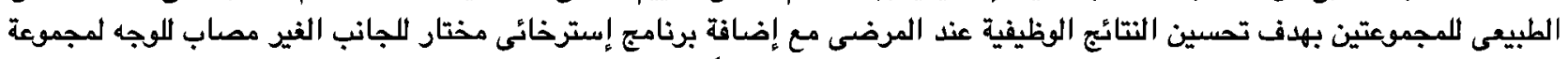

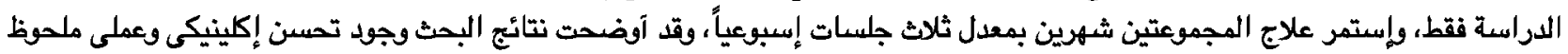

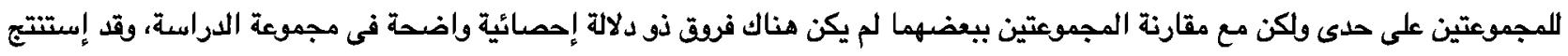

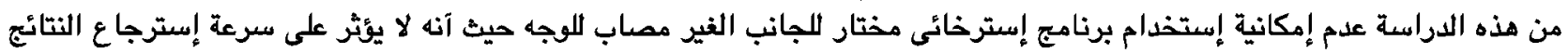
الوظيفية فى مرضى شلل بيل. 